\title{
Valores de Aminoácidos Digestíveis Verdadeiros e Equações de Predição dos Aminoácidos Digestíveis do Grão e de Subprodutos do Trigo para Aves ${ }^{1}$

\author{
Ricardo Vianna Nunes ${ }^{2}$, Horacio Santiago Rostagno ${ }^{3}$, Luiz Fernando Teixeira Albino ${ }^{3}$, \\ Paulo Cezar Gomes ${ }^{3}$, Adriana Helena do Nascimento ${ }^{2}$
}

\begin{abstract}
RESUMO - Foram determinados os coeficientes de digestibilidade verdadeira dos aminoácidos e elaboradas equações de predição dos valores de aminoácidos digestíveis utilizando a composição química de 11 alimentos. Os alimento avaliados foram: farinha morena, farinha de trigo, trigo-grão, triguilho, gérmen de trigo, resíduo de biscoito, resíduo de macarrão e quatro farelos de trigo. Foi utilizado o método de "alimentação forçada" com galos cecectomizados. O delineamento experimental utilizado foi o inteiramente casualizado, com 11 alimentos e um tratamento-jejum, seis repetições e um galo por unidade experimental. Os coeficientes médios de digestibilidade verdadeira dos aminoácidos para farelo de trigo 1, farelo de trigo 2, farelo de trigo 3, farelo de trigo 4, farinha morena, farinha de trigo, resíduo de biscoito, resíduo de macarrão, trigo-grão, triguilho e gérmen de trigo foram 80,$1 ; 76,7 ; 71,8 ; 74,5 ; 84,1 ; 94,1 ; 77,9 ; 90,1 ; 86,0$; 90,$3 ;$ e $93,1 \%$, respectivamente. As equações de predição que melhor estimaram os valores de aminoácidos digestíveis verdadeiros foram aquelas que continham os conteúdos de proteína bruta $(\mathrm{PB})$ e, ou, extrato etéreo (EE), para o aminoácido lisina, e proteína bruta (PB) e, ou, fibra em detergente neutro (FDN), para os aminoácidos metionina, metionina + cistina e treonina e a média dos aminoácidos essenciais, sendo as equações: $\mathrm{Lis}=-0,8805+0,0755 * \mathrm{~PB}+0,0268 * \mathrm{EE}\left(\mathrm{R}^{2}=98 \%\right)$, Met $=-0,0377+0,0183 * \mathrm{~PB}-0,0020 * \mathrm{FDN}$ $\left(R^{2}=99 \%\right), M+C=0,0982+0,0273 * P B-0,0021 * F D N\left(R^{2}=92 \%\right)$, Treo $=-0,2107+0,0401 P B-0,0020 * F D N\left(R^{2}=96 \%\right)$, Essen $=-0,1530+0,0451 * \mathrm{~PB}-0,0024 * \mathrm{FDN}\left(\mathrm{R}^{2}=98 \%\right)$.
\end{abstract}

Palavras-chave: aminoácidos digestíveis, equações de predição, galos cecectomizados

\section{Values of True Digestible Amino Acids and Prediction Equations of Digestible Amino Acids of Wheat Grain and Wheat By-Products for Poultry}

\begin{abstract}
The true digestibility coefficients of amino acids (TDCaa) were determined and digestible amino acids prediction equations obtained, using the chemical composition of 11 feedstuffs. The feedstuffs evaluated were: brown flour meal, wheat flour, wheat grain, wheat grain residue, wheat germ, cookies residue, macaroni residue and, four wheat brans. The method of "precision feeding" with cecectomized adult rooster was utilized. A randomized complete design was used, with 11 feedstuffs and 1 fast, using six replications with 1 rooster per experimental unit. The average of TDC of amino acids, for the wheat bran 1, wheat bran 2, wheat bran 3, wheat bran 4, brown flour meal, wheat flour, cookies residue, macaroni residue, wheat grain, wheat grain residue, wheat germ meal were 80,1; 76,7; 71,$8 ; 74,5 ; 84,1 ; 94,1 ; 77,9 ; 90,1 ; 86,0 ; 90,3$ e 93,1\%, respectively. The best prediction equations obtained for the TDCaa values were those using crude protein (CP) and/or ether extract (EE) for lysine and $\mathrm{CP}$ and/or neutral detergent fiber (NDF) for methionine, methionine + cystine, threonine and the average of the essential amino acids. The equations were: Lys $=-0,8805+0,0755^{*} \mathrm{CP}+0,0268 * \mathrm{EE}\left(\mathrm{R}^{2}\right.$ $=98 \%)$, Met $=-0,0377+0,0183 * \mathrm{CP}-0,0020 * \mathrm{NDF}\left(\mathrm{R}^{2}=99 \%\right), \mathrm{M}+\mathrm{C}=0,0982+0,0273 * \mathrm{CP}-0,0021 * \mathrm{NDF}\left(\mathrm{R}^{2}=92 \%\right), \mathrm{Threo}=$ $-0,2107+0,0401 \mathrm{CP}-0,0020 * \mathrm{NDF}\left(\mathrm{R}^{2}=96 \%\right)$, Essen $=-0,1530+0,0451 * \mathrm{CP}-0,0024 * \mathrm{NDF}\left(\mathrm{R}^{2}=98 \%\right)$.
\end{abstract}

Key Words: cecectomized adults roosters, digestible amino acid, prediction equations

\section{Introdução}

As fontes protéicas representam, aproximadamente, um quarto dos custos de alimentação em rações para as aves. Imbalanços ou deficiência de aminoácidos nas rações podem levar a alterações na produção, afetando de modo negativo o retorno econômico da atividade.

O conhecimento da composição de aminoácidos dos alimentos é importante na formulação de rações. Entretanto, a utilidade destas informações é limitada, uma vez que a quantidade de aminoácidos digestíveis para os animais é bem menor do que aquelas contidas nos alimentos (PARSONS, 1991).

Os aminoácidos não estão prontamente disponíveis para absorção, tornando-se necessário, então, determinar os coeficientes de digestibilidade destes

\footnotetext{
1 Parte da tese apresentada pelo primeiro autor à UFV para obtenção do título de Magister Scientiae.

2 Zootecnista - Departamento de Zootecnia, UFV - 36571-000 - Viçosa, MG. Bolsista CNPq. E.mail: rvnunes@tdnet.com.br

3 Professor do Departamento de Zootecnia, UFV - 36571-000 - Viçosa, MG. Bolsista CNPq.
} 
nos diferentes alimentos, o que possibilitaria o maior aproveitamento desses nutrientes, além de aumento na produtividade e no retorno econômico da produção (FISCHER JR., 1997).

Os valores determinados para a digestibilidade dos aminoácidos têm sido muito questionados, independente do método utilizado, em virtude, provavelmente, do efeito da flora microbiana intestinal presente, principalmente, no ceco das aves. Sabe-se que o ceco das aves é o local de maior atividade microbiana. Assim, a utilização de galos cecectomizados tem sido um procedimento posposto.

A formulação de rações com base em aminoácidos totais é menos eficiente, devido às diferenças na digestibilidade destes aminoácidos em cada alimento (COON, 1991). Portanto, o desconhecimento da quantidade real de aminoácidos digestíveis, nos diferentes alimentos utilizados na formulação, pode acarretar em sub ou superconsumo de aminoácidos, afetando, conseqüentemente, a produção. As exigências em aminoácidos digestíveis são, aproximadamente, 8 a $10 \%$ menores em relação à exigência em aminoácidos totais (PARSONS, 1991).

ROSTAGNO et al. (1995) relataram que a formulação de rações com base em aminoácidos digestíveis e igual conteúdo de lisina e aminoácidos sulfurosos digestíveis para frangos de corte possibilita melhores predição da qualidade da proteína dietética e desempenho das aves, quando comparadas a rações com base em aminoácidos totais, além de oferecer a opção de utilização de alimentos alternativos, menos onerosos na formulação. Os benefícios da formulação de rações com base em proteína digestível ou aminoácidos digestíveis já foram relatados por ALBINO et al. (1992). Assim, a utilização de aminoácidos digestíveis verdadeiros dos alimentos torna-se de grande utilidade na formulação de rações para aves.

A utilização de diferentes metodologias na determinação do conteúdo de aminoácidos digestíveis gera diferentes resultados. Além disso, o fato de as tabelas nacionais não apresentarem as exigências nutricionais expressas na forma de aminoácidos digestíveis tem causado grandes dificuldades de interpretação e enorme restrição para elaboração de rações com base em aminoácidos digestíveis.

Este trabalho foi conduzido com o objetivo de determinar os coeficientes de digestibilidade e a quantidade de aminoácidos digestíveis do grão de trigo e de alguns de seus subprodutos, usando o método de alimentação forçada, com galos Leghorn adultos cecectomizados.
Foram estabelecidas equações de predição, para estimar os valores dos aminoácidos lisina, metionina, metionina + cistina e treonina e a média dos aminoácidos essenciais, dos alimentos estudados.

\section{Material e Métodos}

Foi realizado um ensaio biológico no Laboratório de Animais do Departamento de Zootecnia (DZO) da Universidade Federal de Viçosa (UFV), no mês de julho de 1998, utilizando-se a técnica de alimentação forçada (SIBBALD, 1979) com galos Leghorn adultos e cecectomizados, pesando, em média, $2365 \mathrm{~g} \pm 192 \mathrm{~g}$.

As cirurgias de cecectomia dos galos foram realizadas no Setor de Avicultura do DZO/UFV, usando-se a técnica descrita por PUPA et al. (1998), por intermédio de laparotomia abdominal e anestesia local.

O delineamento experimental utilizado foi o inteiramente casualizado, composto por 11 alimentosteste (quatro farelos de trigo de diferentes fornecedores, farinha morena, farinha de trigo, gérmen de trigo, trigo-grão, triguilho, resíduo de fábrica de biscoito e resíduo de fábrica de macarrão) e um jejum, para determinação das perdas endógenas e metabólicas de aminoácidos, com seis repetições por tratamento e um galo por repetição. Os galos foram alojados em gaiolas individuais de baterias metálicas e, durante um período de adaptação de cinco dias, receberam alimentação em dois turnos de uma hora cada, sendo um pela manhã e outro à tarde, com o objetivo de dilatar o papo.

O período experimental foi de 80 horas. Nas primeiras 24 horas, os galos permaneceram em jejum, para esvaziamento do trato digestivo; após esse período, cada galo foi alimentado com $30 \mathrm{~g}$ do alimento correspondente ao tratamento em questão, divididos em duas vezes, às 8 e 16 h, a fim de evitar regurgitações. $\mathrm{O}$ alimento foi introduzido, por intermédio de um funilsonda, via oral até o papo. Simultaneamente, seis galos permaneceram em jejum. As 56 horas restantes após a primeira alimentação compreenderam o período de coletas de fezes, que foram realizadas duas vezes por dia (8 e 17 h), para evitar fermentação das excretas, depositadas em bandejas revestidas com plásticos, colocadas sob o piso das gaiolas.

A temperatura média registrada no interior da sala, na qual se conduziu o experimento, foi de $20,4 \pm 3,9^{\circ} \mathrm{C}$, sendo a média mínima e máxima de $17,1 \pm 2,0$ e $23,8 \pm 1,9^{\circ} \mathrm{C}$, respectivamente. Utilizaram-se aquecedores no período da noite, para que os animais tivessem o maior conforto térmico. 
776 Rev. bras. zootec.

O material recolhido foi quantificado e armazenado no freezer. Ao final do período de coleta, as amostras foram homogeneizadas e secas em estufas de ventilação forçada a $55^{\circ} \mathrm{C}$, possibilitando a determinação dos valores de matéria seca e nitrogênio total, juntamente com as amostras dos alimentos. As análises foram realizadas no Laboratório de Nutrição Animal do DZO/ UFV, segundo as técnicas descritas por SILVA (1998).

Os aminogramas dos alimentos e das excretas foram realizados no Laboratório de Nutrição Animal da Ajinomoto na França.

Os valores obtidos no tratamento-jejum foram utilizados para realizar as correções correspondentes às perdas metabólicas e endógenas de aminoácidos.

Conhecendo-se as quantidades de aminoácidos ingeridos e excretados, bem como a fração metabólica e endógena obtida com galos em jejum, foram determinados os coeficientes de digestibilidade verdadeira e o conteúdo digestível verdadeiro de cada aminoácido nos alimentos, por meio da fórmula, proposta por ROSTAGNO e FEATHERSTON (1977).

Como procedimento estatístico, aplicou-se o teste de comparação de médias Student Newman-Keuls, a $5 \%$ de probabilidade, entre os valores médios dos coeficientes de digestibilidade verdadeira dos aminoácidos.

As análises de regressão foram realizadas por regressão linear simples e múltipla, utilizando-se o Método Stepwise de Eliminação Indireta (Backward), por intermédio do Sistema de Análises Estatísticas SAEG (1999).

\section{Resultados e Discussão}

\section{Composição aminoacídica}

Os valores de aminoácidos dos alimentos estudados são apresentados na Tabela 1. Os resultados dos farelos de trigo são similares aos obtidos pela EMBRAPA (1991), pelo WPSA (1992) e NATIONAL RESEARCH COUNCIL - NRC (1994). Neste trabalho, os valores dos aminoácidos metionina, cistina, treonina, arginina, histidina e fenilalanina foram inferiores e somente o valor de tirosina foi superior ao obtido por SCOTT et al. (1982). TEIXEIRA (1998) também encontrou resultados inferiores para os aminoácidos treonina, cistina, histidina, fenilalanina e tirosina e maiores para a isoleucina. Para a tirosina, o resultado da EMBRAPA (1991) foi o que mais se aproximou dos encontrados neste estudo.

Os valores obtidos para farinha morena foram os que mais se aproximaram dos obtidos pelo WPSA
(1992) e NRC (1994), com exceção da ácido glutâmico, da serina e tirosina, que foram menores. Para o triguilho, os valores de lisina, alanina, ácido aspártico e tirosina estão abaixo e os de ácido glutâmico, acima dos citados pela EMBRAPA (1991). O trigo-grão apresentou valores mais próximos aos publicados pelo WPSA (1992) e NRC (1994) e inferirores aos obtidos por TEIXEIRA (1998).

Com relação à farinha de trigo e ao resíduo de macarrão, os valores que mais se aproximaram foram os encontrados no WPSA (1992). Para o resíduo de biscoitos, somente os valores de metionina, cistina e histidina aproximaram-se dos publicados pelo WPSA (1992). O gérmen de trigo teve grande variação, quando comparado aos apresentados na literatura, sendo a lisina, metionina, treonina, isoleucina, valina e histidina os aminoácidos que mais se aproximaram dos valores obtidos por TEIXEIRA (1998).

Para comparação dos valores dos resíduos macarrão e biscoito, foram utilizados os valores tabelados encontrados para o resíduo de panificação, pois foram os que mais se assemelharam em relação à composição química e aminoacídica.

Valores dos coeficientes de digestibilidade verdadeira dos aminoácidos e valores de aminoácidos digestiveis verdadeiros

Os coeficientes médios de digestibilidade dos aminoácidos essenciais e não-essenciais dos alimentos-teste são apresentados nas Tabelas 2 e 3, respectivamente. As variações observadas nos coeficientes de digestibilidade dos aminoácidos entre os alimentos evidenciam a grande importância em se conhecer a digestibilidade desses nutrientes, para a formulação de rações, utilizando-se alimentos alternativos em substituição ao milho e farelo de soja, para obtenção do máximo desempenho das aves.

Entre os alimentos estudados, a farinha de trigo foi a que apresentou os maiores coeficientes de digestibilidade em 11 aminoácidos estudados, entre eles a arginina, com 99,44\%; os aminoácidos sulfurados (metionina e cistina), com $94,11 \%$; a lisina, com $93,81 \%$; e a média dos essenciais, com $95,01 \%$, com exceção da treonina, com $87,11 \%$. O gérmen de trigo apresentou o maior coeficiente para a lisina e, com exceção da treonina e cistina, todos os outros aminoácidos tiveram coeficiente de digestibilidade acima de $90 \%$. Quanto à farinha de trigo, somente os aminoácidos treonina, alanina e ácido aspártico apresentaram valores inferiores a $90 \%$ de digestibilidade.

Com exceção do resíduo de biscoito, todos os alimentos com alto teor de fibra, como os farelos de 


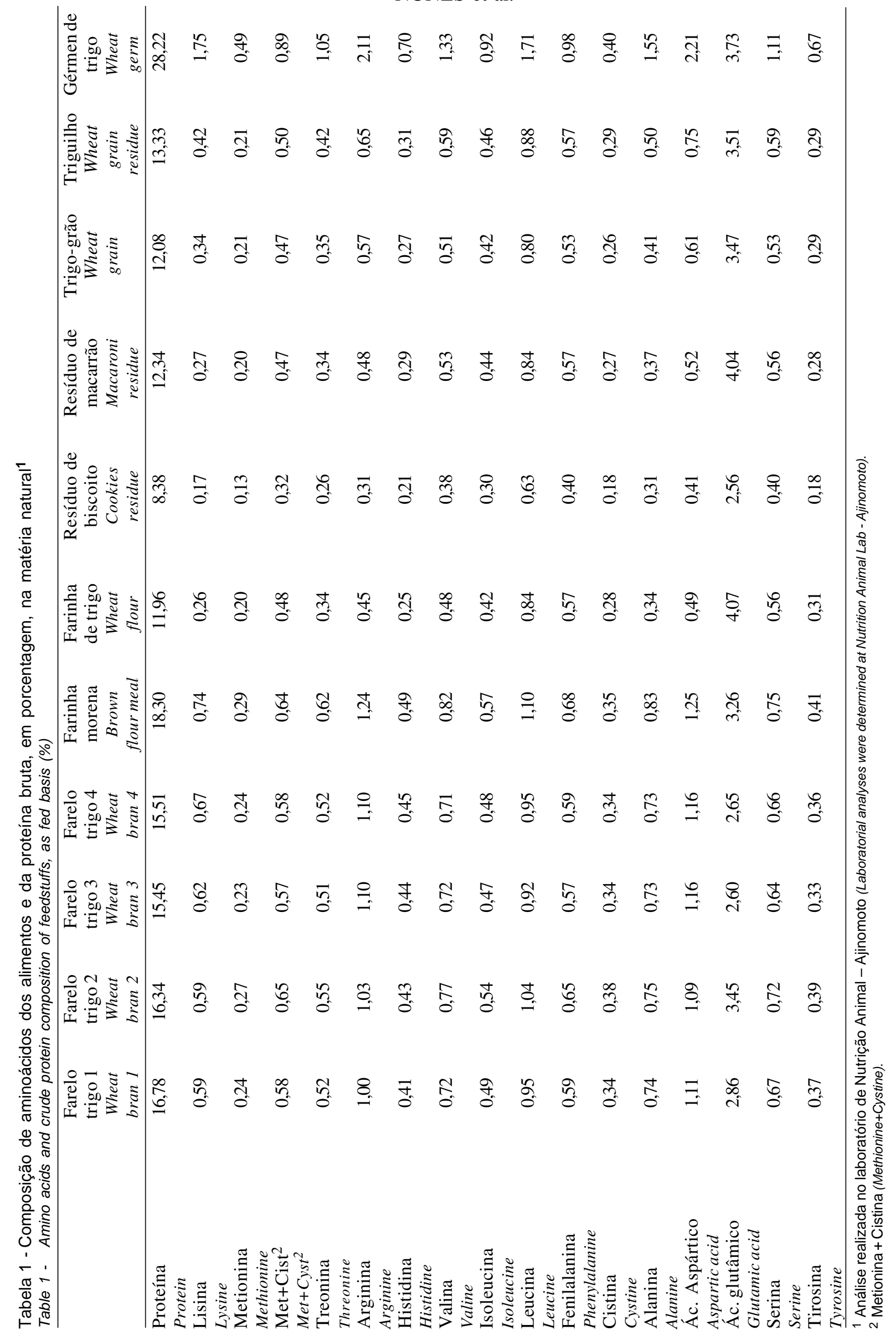




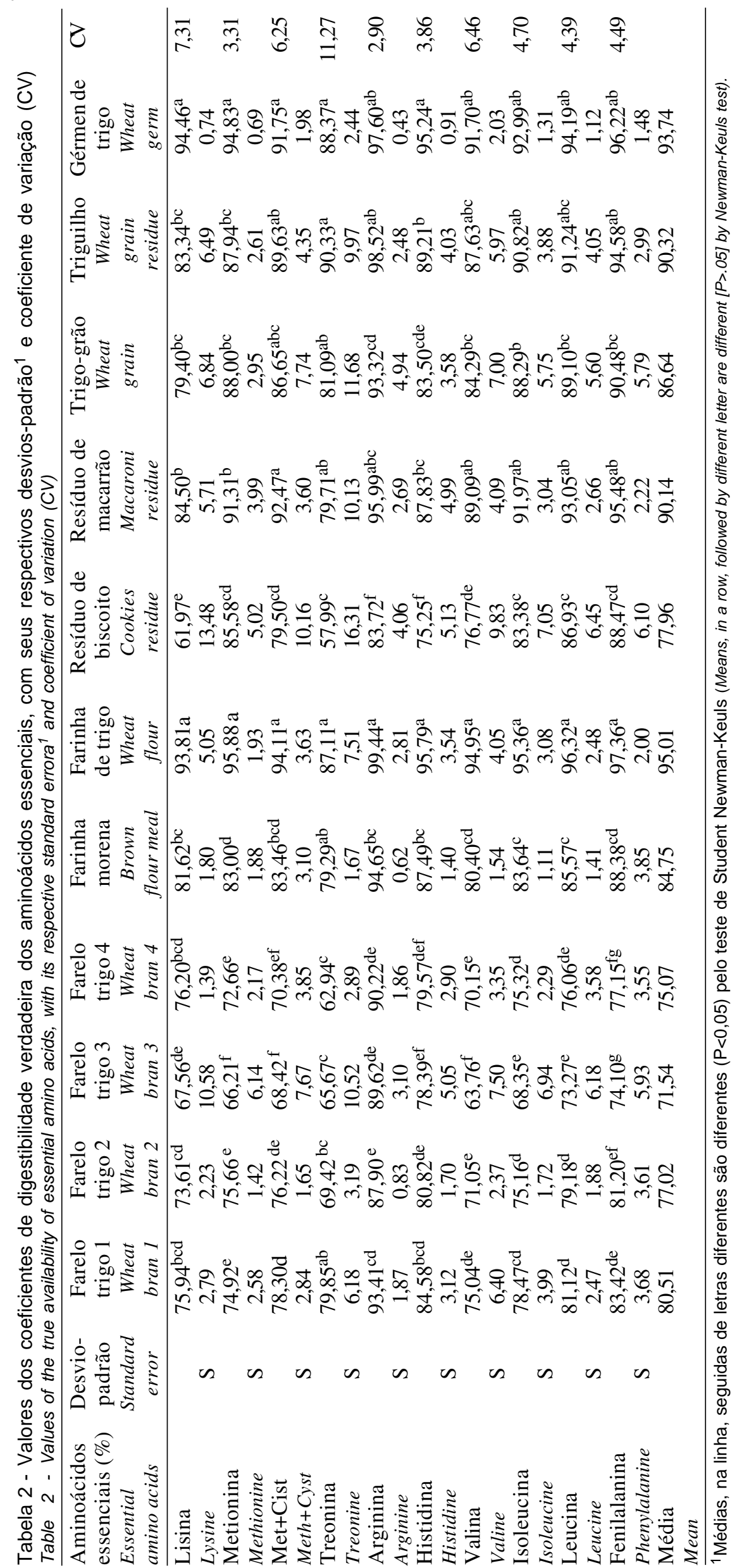




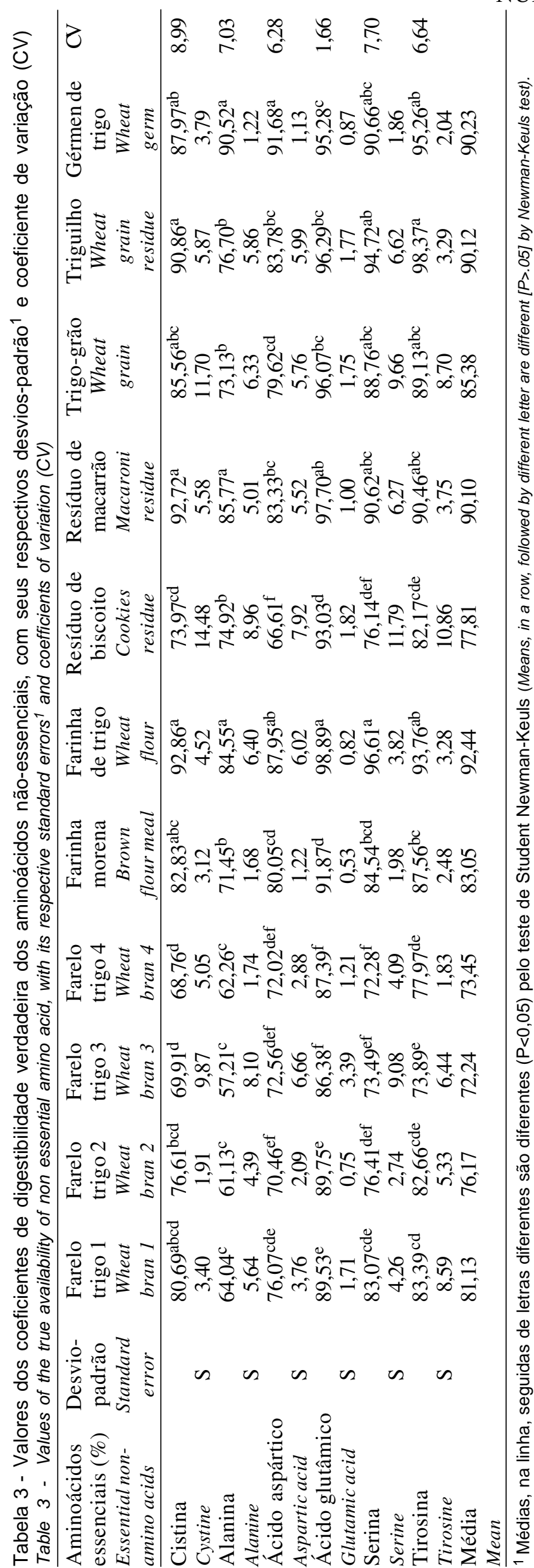

NUNES et al.

trigo e a farinha morena, apresentaram menores coeficientes de digestibilidade, tanto para os aminoácidos essenciais, quanto para os não-essenciais, sendo o farelo de trigo 3 o que apresentou os piores resultados para todos os aminoácidos estudados, com exceção da cistina, serina e do ácido aspártico. Segundo PARSONS (1984), a fibra dos alimentos pode reduzir a digestibilidade dos aminoácidos, aumentando suas perdas endógenas. COON (1991) relatou que a fibra aumenta a atividade da células da mucosa intestinal e a produção de muco, diminuindo a digestibilidade de aminoácidos, pela formação de um gel em torno dos mesmos, ou se ligando fortemente a enzimas digestivas, o que poderia explicar os baixos valores de digestibilidade encontrados nestes alimentos.

$\mathrm{O}$ triguilho foi o alimento que apresentou maior digestibilidade $(90,33 \%)$ para treonina. A farinha de trigo, o gérmen de trigo, o triguilho e o resíduo de macarrão foram os que mais se destacaram, apresentando sempre os quatro maiores coeficientes de digestibilidade para todos os aminoácidos.

Para lisina, treonina e arginina, os piores resultados de digestibilidade foram apresentados pelo resíduo de biscoito, em relação aos alimentos estudados. Comparando-se os coeficientes de digestibilidade da lisina, treonina, metionina, cistina, arginina e valina deste alimento com os valores de literatura, para o resíduo de panificação, constatou-se que PARSONS (1991) e PARSONS e BAKER (1994) observaram resultados semelhantes para o coeficiente de digestibilidade verdadeira destes aminoácidos.

O grão de trigo apresentou digestibilidade intermediária entre os alimentos estudados. Resultados semelhantes de coeficiente de digestibilidade verdadeira para lisina, treonina, metionina, cistina, arginina e valina foram encontrados por PARSONS (1991) e PARSONS E BAKER (1994).

Os resultados de digestibilidade para os aminoácidos essenciais do farelo de trigo 1 (com exceção da metionina e arginina, que foram menores) e do farelo de trigo 2 (com exceção da histidina e valina, que foram maiores, e da metionina, com valores menores) foram semelhantes aos encontrados por ALBINO et al. (1992b). Na comparação com o farelo de trigo 3 , somente a metionina e arginina apresentaram, neste trabalho, resultados semelhantes aos encontrados por ALBINO et al. (1992), sendo que os outros aminoácidos essenciais 
apresentaram coeficientes abaixo dos encontrados por aquele autores.

Para o farelo de trigo 4, os coeficientes de digestibilidade dos aminoácidos lisina, metionina e arginina, encontrados neste trabalho, foram superiores aos encontrados por ALBINO et al. (1992b), entretanto, os outros aminoácidos essenciais foram inferiores, quando comparados aos obtidos por esses autores. Com relação aos aminoácidos nãoessenciais, a farinha de trigo foi o alimento que apresentou os maiores coeficientes de digestibilidade, com média de $92,44 \%$. Já o farelo de trigo 3 foi o alimento que apresentou os menores coeficientes de digestibilidade, 72,24\%.

$\mathrm{Na}$ Tabela 4, estão relacionados os valores de aminoácidos digestíveis dos alimentos. Em relação aos resultados dos desvios-padrão dos coeficientes de digestibilidade verdadeira dos aminoácidos calculados, os quais apresentaram baixos valores, pode-se concluir que o método utilizado apresentou boa precisão e eficácia para estimar a digestibilidade verdadeira dos aminoácidos.

Para a farinha de trigo e o triguilho, a arginina foi o aminoácido que apresentou semelhante composição tanto para aminoácidos totais, quanto para aminoácidos digestíveis verdadeiros. O farelo de trigo 3 apresentou as maiores diferenças entre as quantidades de aminoácidos totais e digestíveis, sendo que para a alanina foi de $74,64 \%$.

Equações de predição dos valores de aminoácidos digestiveis verdadeiros dos alimentos

As equações de regressão múltipla, para estimar os valores de lisina (Lis), metionina (Met), metionina + cistina $(\mathrm{M}+\mathrm{C})$ e treonina (Treo), e a média dos aminoácidos essenciais (Essen) digestíveis verdadeiros dos alimentos encontram-se na Tabela 5. Foram utilizadas as variáveis proteína bruta (PB), extrato etéreo (EE), matéria mineral $(\mathrm{MM})$, fibra bruta $(\mathrm{FB})$, fibra em detergente neutro (FDN), fibra em detergente ácido (FDA), cálcio (Ca) e fósforo (P).

As equações foram calculadas pelo Método Stepwise de Eliminação Indireta (Backward), o qual fornece a contribuição de cada variável dentro da análise de regressão múltipla. O teste $\mathrm{T}$, com significância de 5\% de probabilidade, foi utilizado isoladamente dentro de cada variável que compõe a equação, com a finalidade de se obterem equações com maior precisão.

Os coeficientes de determinação $\left(\mathrm{R}^{2}\right)$ variaram de 0,99 a 0,85 , utilizando-se equações que variaram de quatro a uma variável. Para lisina, a equação com $\mathrm{PB}$ e EE obteve $\mathrm{R}^{2}$ de 0,98 . Para metionina, metionina + cistina e treonina e a média dos aminoácidos essenciais, as equações com as variáveis PB e FDN resultaram, respectivamente, em valores de $\mathrm{R}^{2}$ de 0,$99 ; 0,92 ; 0,96$; e 0,98 . A proteína bruta, entre todos os parâmetros utilizados para determinar as equações de predição, foi a que demonstrou maior correlação positiva $( \pm 95 \%)$ para todos os aminoácidos estudados.

Na Tabela 6, estão relacionados os valores dos aminoácidos digestíveis verdadeiros observados no ensaio biológico, os estimados por equações de predição e a diferença média ao quadrado entre os valores estimados e observados.

Para o resíduo de biscoito, somente foi possível estimar o valor do aminoácido lisina por intermédio da equação que continha as variáveis PB e EE, com $\mathrm{R}^{2}$ de $98 \%$. Entretanto, para os outros aminoácidos, metionina, metionina + cistina e treonina, e a média dos essenciais, não foi possível estimar estes valores, pois as equações que continham FDN impossibilitaram sua predição, sendo que esta variável não foi determinada em análise laboratorial.

A equação utilizada para estimar os valores de lisina tiveram diferença média entre os valores observados e estimados de $19,35 \%$, sendo que o trigo-grão apresentou a maior diferença com $50,10 \%$, entretanto, o gérmen de trigo apresentou diferença de apenas $2,74 \%$. Para as outras equações, a diferença média foi de 5,06; 5,00; 5,19; e $2,89 \%$, respectivamente, para metionina, metionina + cistina e treonina e a média dos essenciais.

O gérmen de trigo foi o alimento que apresentou as menores diferenças entre os valores observados e os estimados, com 2,$74 ; 0,12 ; 2,51 ; 0,13$; e $0,43 \%$, respectivamente, para lisina, metionina, metionina + cistina, treonina e a média dos essenciais. 


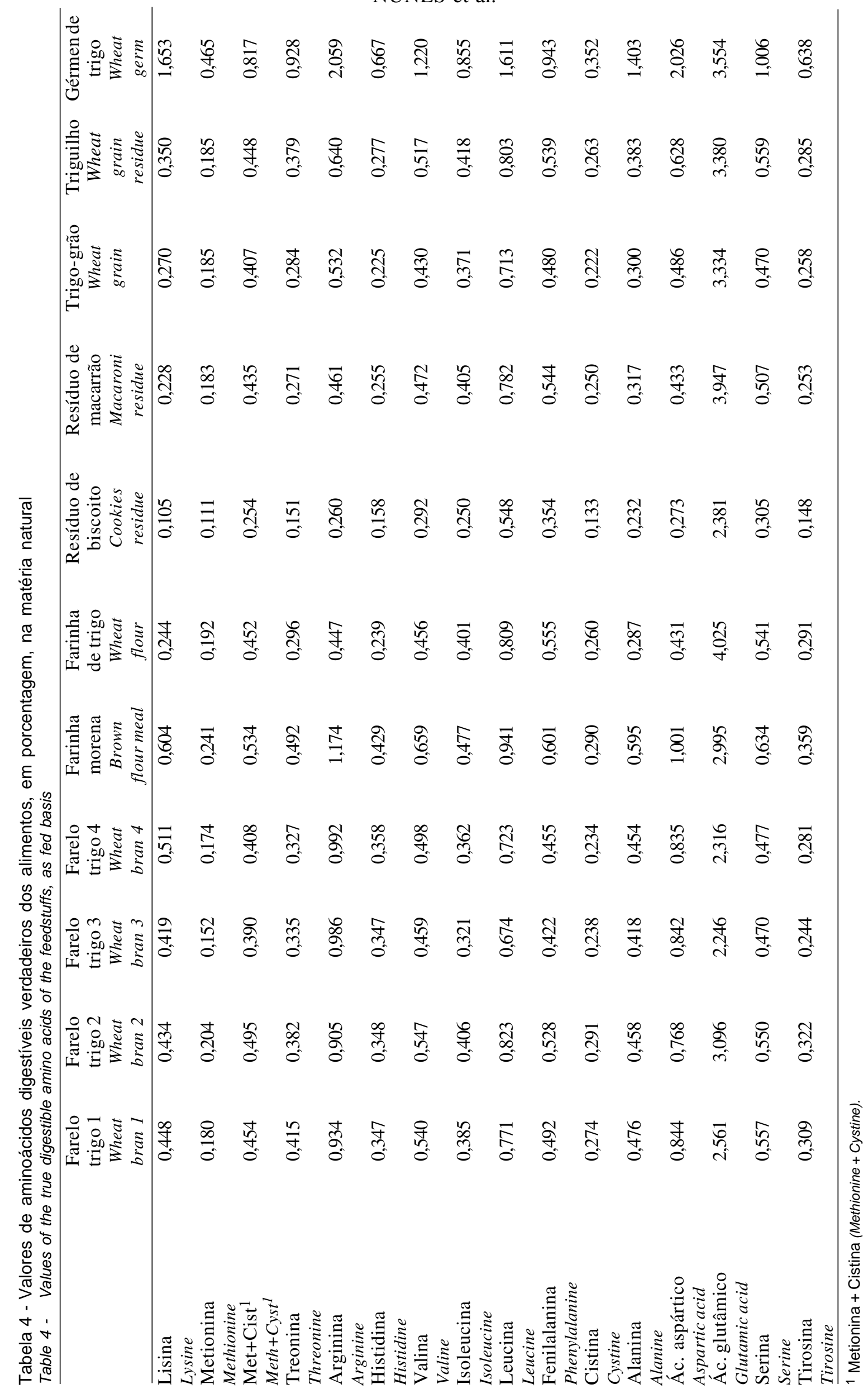


Tabela 5 - Equações de predição dos valores de lisina, metionina, metionina + cistina e treonina e média dos aminoácidos essenciais digestíveis verdadeiros, a partir da composição química ${ }^{1}$ dos alimentos

Table 5 - Predition of equation of the values of lysine, methionine, methionine + cystine and treonine and mean of the true digestible essential amino acid, in the chemical composition ${ }^{1}$ of the feedstuffs

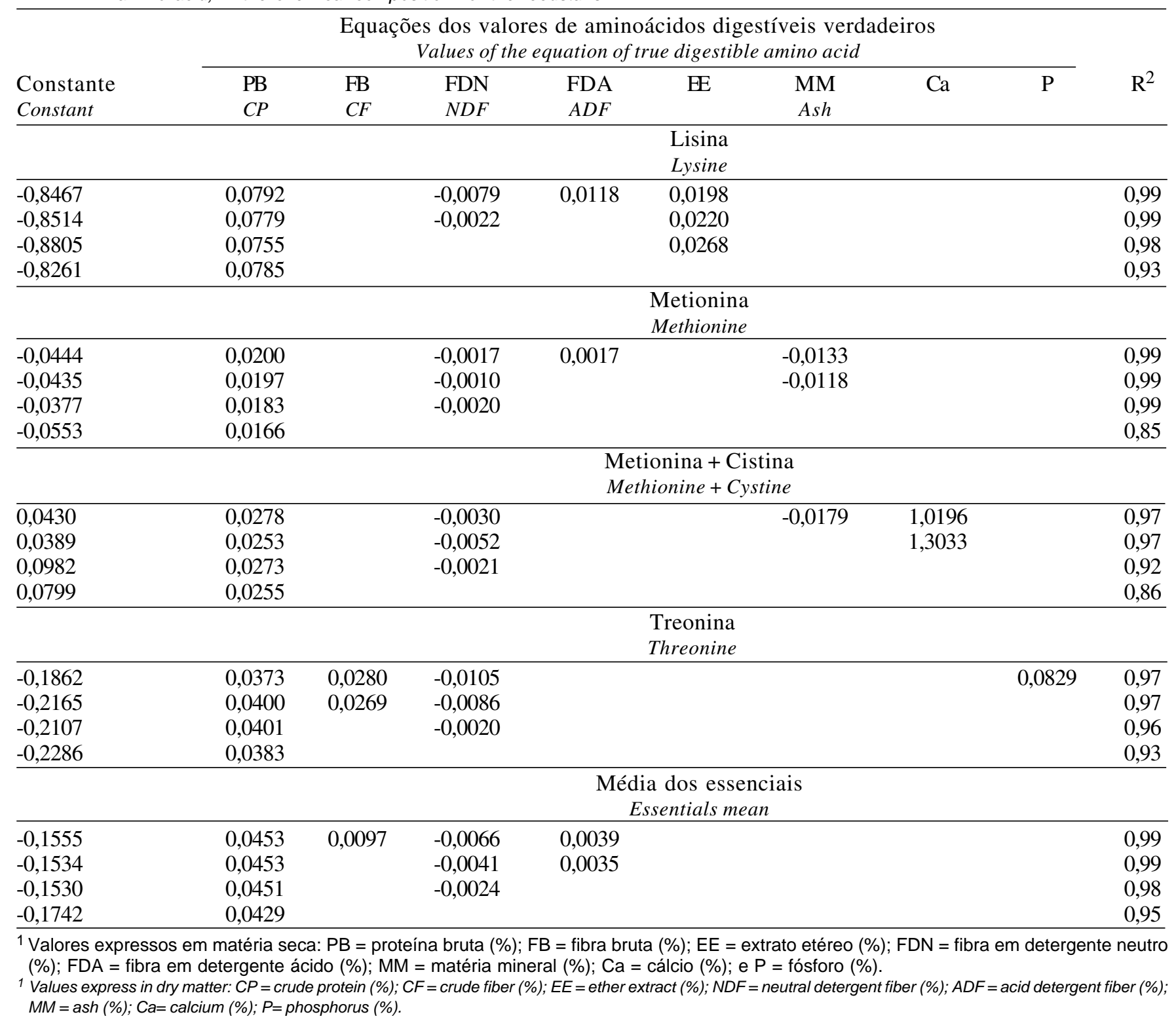


NUNES et al.

Tabela 6 - Estimativa dos valores de lisina (Lis), metionina (Met), metionina + cistina $(M+C)$, treonina (Treo) e aminoácidos essenciais (Essen) digestíveis verdadeiros

Table 6 - Estimate of the values of lysine (Lys), methionine (Meth), methionine + cystine $(M+C)$, threonine (Thr) and true digestible essential amino acids (Essen)

\begin{tabular}{|c|c|c|c|c|c|c|c|c|c|c|}
\hline \multirow[b]{2}{*}{$\begin{array}{l}\text { Alimentos } \\
\text { Feedstuffs }\end{array}$} & \multicolumn{8}{|c|}{$\begin{array}{l}\text { Lis }=-0,8805+0,0755 * \mathrm{~PB}+0,0268 * \mathrm{EE} \\
\text { Lys }=-0.8805+0.0755^{*} C P+0.0268 * E E \\
\mathrm{Met}=-0,0377+0,0183 * \mathrm{~PB}-0,0020 * \mathrm{FDN} \\
\text { Meth }=-0.0377+0.0183 * C P-0.0020 * N D F \\
\mathrm{M}+\mathrm{C}=0,0982+0,0273 * \mathrm{~PB}-0,0021 * \mathrm{FDN} \\
M+C=0.0982+0.0273 * C P-0.0021 * N D F \\
\text { Treo }=-0,2107+0,0401 \mathrm{~PB}-0,0020 * \mathrm{FDN} \\
T h r=-0.2107+0.0401 C P-0.0020 * N D F \\
\text { Essen }=-0,1530+0,0451 * \mathrm{~PB}-0,0024 * \mathrm{FDN} \\
\text { Essen }=-0.1530+0.0451 * C P-0.0024 * N D F\end{array}$} & \multicolumn{2}{|c|}{$\begin{array}{l}\left(\mathrm{R}^{2}=0,98\right) \\
\left(\mathrm{R}^{2}=0,98\right) \\
\left(\mathrm{R}^{2}=0,99\right) \\
\left(\mathrm{R}^{2}=0,99\right) \\
\left(\mathrm{R}^{2}=0,92\right) \\
\left(\mathrm{R}^{2}=0,92\right) \\
\left(\mathrm{R}^{2}=0,96\right) \\
\left(\mathrm{R}^{2}=0,96\right) \\
\left(\mathrm{R}^{2}=0,98\right) \\
\left(\mathrm{R}^{2}=0,98\right)\end{array}$} \\
\hline & $\begin{array}{l}\text { Lis. } \\
\text { obs. }{ }^{1}\end{array}$ & $\begin{array}{l}\text { Lis. } \\
\text { est. }^{2}\end{array}$ & $\begin{array}{l}\text { Met. } \\
\text { obs. }\end{array}$ & $\begin{array}{l}\text { Met. } \\
\text { est. }\end{array}$ & $\begin{array}{l}\mathrm{M}+\mathrm{C} \\
\text { obs. }\end{array}$ & $\begin{array}{l}\mathrm{M}+\mathrm{C} \\
\text { est. }\end{array}$ & $\begin{array}{l}\text { Treo. } \\
\text { obs. }\end{array}$ & $\begin{array}{l}\text { Treo. } \\
\text { est. }\end{array}$ & $\begin{array}{c}\text { Essen. } \\
\text { obs. }\end{array}$ & $\begin{array}{c}\text { Essen. } \\
\text { est. }\end{array}$ \\
\hline $\begin{array}{l}\text { Farelo de trigo } 1 \\
\text { Wheat bran } 1\end{array}$ & 0,505 & 0,609 & 0,203 & 0,224 & 0,512 & 0,526 & 0,396 & 0,463 & 0,562 & 0,598 \\
\hline $\begin{array}{l}\text { Farelo de trigo } 2 \\
\text { Wheat bran } 2\end{array}$ & 0,491 & 0,574 & 0,231 & 0,223 & 0,560 & 0,521 & 0,387 & 0,453 & 0,574 & 0,588 \\
\hline $\begin{array}{l}\text { Farelo de trigo } 3 \\
\text { Wheat bran } 3\end{array}$ & 0,473 & 0,538 & 0,171 & 0,180 & 0,440 & 0,467 & 0,329 & 0,387 & 0,508 & 0,511 \\
\hline $\begin{array}{l}\text { Farelo de trigo } 4 \\
\text { Wheat bran } 4\end{array}$ & 0,577 & 0,517 & 0,196 & 0,183 & 0,460 & 0,472 & 0,333 & 0,392 & 0,544 & 0,517 \\
\hline $\begin{array}{l}\text { Trigo-grão } \\
\text { Wheat grain }\end{array}$ & 0,309 & 0,206 & 0,211 & 0,194 & 0,465 & 0,453 & 0,274 & 0,322 & 0,446 & 0,444 \\
\hline $\begin{array}{l}\text { Farinha morena } \\
\text { Brown flour meal }\end{array}$ & 0,685 & 0,731 & 0,273 & 0,270 & 0,605 & 0,588 & 0,471 & 0,549 & 0,699 & 0,696 \\
\hline $\begin{array}{l}\text { Farinha de trigo } \\
\text { Wheat flour }\end{array}$ & 0,282 & 0,223 & 0,222 & 0,212 & 0,522 & 0,472 & 0,291 & 0,340 & 0,471 & 0,466 \\
\hline $\begin{array}{l}\text { Res. de biscoito } \\
\text { Cookies residue }\end{array}$ & 0,114 & 0,149 & 0,120 & - & 0,275 & - & 0,127 & - & 0,268 & - \\
\hline $\begin{array}{l}\text { Res. de macarrão } \\
\text { Macaroni residue }\end{array}$ & 0,259 & 0,215 & 0,208 & 0,215 & 0,495 & 0,477 & 0,297 & 0,348 & 0,457 & 0,475 \\
\hline $\begin{array}{l}\text { Triguilho } \\
\text { Wheat grain residue }\end{array}$ & 0,397 & 0,327 & 0,210 & 0,196 & 0,508 & 0,466 & 0,301 & 0,353 & 0,516 & 0,478 \\
\hline $\begin{array}{l}\text { Gérmen de trigo } \\
\text { Wheat germ }\end{array}$ & 1,872 & 1,822 & 0,526 & 0,526 & 0,925 & 0,948 & 0,909 & 1,049 & 1,268 & 1,263 \\
\hline $\begin{array}{l}\text { Média } \\
\text { Mean }\end{array}$ & 0,542 & 0,537 & 0,234 & 0,232 & 0,524 & 0,522 & 0,438 & 0,437 & 0,574 & 0,572 \\
\hline $\begin{array}{l}\mathrm{S}^{3} \mathrm{~d}^{2} \\
\text { Média }^{4} \mathrm{~d}^{2} \\
\text { Mean }^{4}\end{array}$ & & $\begin{array}{l}0,0521 \\
0,0047\end{array}$ & & $\begin{array}{l}0,0014 \\
0,0001\end{array}$ & & $\begin{array}{l}0,0080 \\
0,0008\end{array}$ & & $\begin{array}{l}0,0086 \\
0,0009\end{array}$ & & $\begin{array}{l}0,0041 \\
0,0004\end{array}$ \\
\hline
\end{tabular}

1 Valor de aminoácido digestível verdadeiro observado in vivo, em porcentagem de matéria seca.

2 Valor de aminoácido digestível verdadeiro estimado, em porcentagem de matéria seca.

3 Somatória ao quadrado das diferenças entre os valores estimados e observados.

4 Média das diferenças.

1 Value of true digestible amino acid observed in vivo, in dry matter percentage.

2 Value of estimated true digestible amino acid, in dry matter percentage.

3 Amount to square of the difference among the estimate and observed values.

4 Mean of the differences.

\section{Conclusões}

Os coeficientes médios de digestibilidade verdadeira dos aminoácidos essenciais para os alimentos farelo de trigo 1 , farelo de trigo 2, farelo de trigo 3, farelo de trigo 4 , farinha morena, farinha de trigo, resíduo de biscoito, resíduo de macarrão, trigo-grão, triguilho e gérmen de trigo foram, respectivamente, 80,$5 ; 77,0 ; 71,5 ; 75,1 ; 84,8 ; 95,0 ; 78,0 ; 90,1 ; 86,6 ; 90,3$; e 93,7. Os valores de coeficientes de digestibilidade dos aminoácidos não-essenciais para os alimentos farelo de trigo 1 , farelo de trigo 2 , farelo de trigo 3 , farelo de trigo 4 , farinha morena, farinha de trigo, resíduo de biscoito, resíduo de macarrão, trigo-grão, 
784 Rev. bras. zootec.

triguilho e gérmen de trigo foram, respectivamente, 79,$5 ; 76,2 ; 72,2 ; 73,5 ; 83,1 ; 92,4 ; 77,8 ; 90,1 ; 85,4 ; 90,1$; e 91,9 . Os coeficientes de digestibilidade verdadeira dos aminoácidos essenciais dos alimentos pobres em fibras foram maiores, quando comparados com os alimentos ricos em fibra. As equações de predição que melhor estimaram os valores de aminoácidos digestíveis verdadeiros foram as que continham as variáveis $\mathrm{PB}$ e EE, para o aminoácido lisina, e PB e FDN, para os aminoácidos metionina, metionina + cistina e treonina, e a média dos aminoácidos essenciais, as quais foram as mais sensíveis aos valores dos aminoácidos digestíveis verdadeiros estudados: Lis $=-0,8805+0,0755 * \mathrm{~PB}+0,0268 * \mathrm{EE}\left(\mathrm{R}^{2}=98 \%\right)$, Met $=-0,0377+0,0183 * \mathrm{~PB}-0,0020 * \mathrm{FDN}$ $\left(\mathrm{R}^{2}=99 \%\right), \mathrm{M}+\mathrm{C}=0,0982+0,0273 * \mathrm{~PB}-0,0021 * \mathrm{FDN}$ $\left(\mathrm{R}^{2}=92 \%\right)$, Treo $=-0,2107+0,0401 \mathrm{~PB}-0,0020 * \mathrm{FDN}$ $\left(\mathrm{R}^{2}=96 \%\right)$, Essen $=-0,1530+0,0451 * \mathrm{~PB}-$ $0,0024 * \mathrm{FDN}\left(\mathrm{R}^{2}=98 \%\right)$.

\section{Referências Bibliográficas}

ALBINO, L.T.F., ROSTAGNO, H.S., SANT'ANNA, R. et al. 1992. Determinação dos valores de aminoácidos metabolizáveis e proteína digestível de alimentos para aves. R. Soc. Bras. Zootec., 21(6):1059-1068.

COON, C.N. Optimizing ingrediente utilization trhough a better understanding of aminoacid biovailability. In: TECHNICAL SYMPOSIA, Aruba, 1991. Proceedings... Aruba: NOVUS INTERNATIONAL, 1991. p.11-40.

EMPRESA BRASILEIRA DE PESQUISA AGROPECUÁRIA EMBRAPA. 1991. Centro Nacional de Pesquisa de Suínos e Aves (CNPSA) - CNPSA. Tabela de composição química e valores energéticos de alimentos para suínos e aves. 3.ed. Concórdia-SC, EMBRAPA-CNPSA. 97p. [Documento 19].

FISCHER JR., A.A. Valores de energia metabolizável e de aminoácidos digestíveis de alguns alimentos para aves. Viçosa, UFV, 1997. 55p. Dissertação (Mestrado em Zootecnia) - Universidade Federal de Viçosa, 1997.
NATIONAL RESEARCH COUNCIL - NRC. 1994. Nutrient requirements of poultry. 9.ed. Washington: National Academy of Sciences. 155p.

PARSONS, C.M. Broiler feed formulation on a digestible amino acid basis. In: LATIN AMERICAN POULTRY CONGRESS, 12, Quito, 1991. Anais... Quito, 1991. p.1-8.

PARSONS, C.M. 1984. Influence of caecectomy and source of dietary fibre or starch on excretion of endogenous amino acids by laying hens. Brit. J. Nutr., 51:541-548.

PARSONS, C.M., BAKER, D.H. The concept and use of ideal proteins in the feeding of noruminants. In: REUNIÃO ANUAL DA SOCIEDADE BRASILEIRA DE ZOOTECNIA, 31 , Maringá, 1994. Anais... Maringá, SBZ, 1994. p.120-128.

PUPA, J.M.R., LEÃO, M.I., CARVALHO, A.U. et al. 1998. Cecectomia em galos sob anestesia local e incisão abdominal. Arq. Bras. Med. Vet. Zootec., 50(5):531-535.

ROSTAGNO, H.S., FEATHERSTON, W.R. 1977. Estudos de métodos para determinar disponibilidade de aminoácidos em pintos. R. Soc. Bras. Zootec., 6(1):64-76.

ROSTAGNO, H.S., PUPA, J.M.R., PACK, M. 1995. Diet formulation for broilers based on total versus digestible amino acids. J. Appl. Poult. Sci. 4:293-299.

SCOTT, M.L., NESHEIM, M.C., YOUNG, R.J. 1982. Nutrition of the chicken. 3.ed. Ithaca, NY. 562p.

SIBBALD, I.R. 1979. A bioassay for available amino acids and true metabolizable energy in feedstuffs. Poult. Sci. 58(3):668-673.

SILVA, D.J. 1998. Análise de alimentos (métodos químicos e biológicos). $1^{\mathrm{a}}$ reimpressão. Viçosa: UFV. 166p.

TEIXEIRA, A.S. 1998. Tabelas de composição dos alimentos e exigências nutricionais. Alimentos e alimentação dos animais. UFLA/FAEPE. v.2. p.98.

UNIVERSIDADE FEDERAL DE VIÇOSA - UFV. 1999. Manual de utilização do programa SAEG (Sistema para Análise Estatísticas e Genéticas). Viçosa. 59p.

WPSA. 1992. European amini acid table. 1.ed., 113p.

Recebido em: $15 / 02 / 00$

Aceito em: 04/01/01 